\title{
Self-Efficacy: The Predictor of Educational Performance among University Students
}

\author{
*Ishfaq Ahmed, Tehmina Fiaz Qazi, Shaista Jabeen \\ Hailey College of Commerce, University of the Punjab, Pakistan \\ *ishfakahmed@gmail.com
}

\begin{abstract}
The basic intention of the present research was to explore the association between perceived academic performance and self-efficacy level of the students as it has been an un-explored research area in the Pakistan. Students were selected as an obvious target population. Sample consisted of 250 university students. Questionnaire was used as a data collection instrument. Major portion of the questionnaire had been taken form the research work done by Sherer et al. (1982). Out of 250 students, 212 students contributed in the data collection comprising $85 \%$ response rate for the study. SPSS 16.0 was used to analyze data. Findings of the study establish a weak positive association between level of self-efficacy (IV) and DV (perceived academic performance) as IV causes only 3.6\% (.036) change in DV (academic performance). Hence, there is a weak dependency of perceived academic performance of students upon their level of selfefficacy.
\end{abstract}

Key Words: Self-efficacy, academic performance, students, Pakistan

\section{Introduction}

Confidence is the pivot to success. Believing one's own strengths supports one even under undesirable situations and conditions. Revival from setbacks of life is essential of survival for human beings. Whether personally or at professional level, self reliance matters a lot achieving the aims set by an individual. Being successful requires consistent performance and this heavily depends upon how an individual deals with the situations or changes coming forth in his life.

This confidence or believe in self is termed as self-efficacy in behavioral sciences. It can be inferred that Selfefficacy means self-confidence, self-reliance, and trust on oneself. Self-efficacy is regarded as one's optimistic self-reliance. It is the self-belief that one can build up; the expertise to carry out innovative or complicated responsibilities and to deal with alterations in performance. When an individual recognizes self-efficacy, it enables him setting goals, attempting to achieve them; boosts determination and revival from dissatisfaction and malfunctioning. It can be observed as a constructive viewpoint or practical technique to deal with the complications. It is the skill to effectively handle undesired changes (The Concept of Self-Efficacy). Csikszentmihalyi (1997) proposed that belief of an individual to become successful encourages him to do the set task successfully. Individuals with lower self efficacy level usually run from the difficult situations rather than never try to accomplish the difficult tasks. Sometimes individuals overrate their self-efficacy that they can do the tasks which they are not actually capable of. Resultantly, they have to face complications.

Bandura (1977) clarified self-efficacy as a sportsperson's trust that he has the required talent to generate a desired output. Self-efficacy is circumstances based, which means a person can be self-assured at one point, but not in another, though they are interconnected. Bandura (1997) also argued that self-efficacy determines a sportsperson's preferences; the attempts he makes to do well at a job and intensity of his determination in case he fails to perform well. Significance of self-efficacy proves its existence even in daily life examples. When the players of any cricket, hockey or football team go to different countries to play, first of all it is their self-confidence that assists them. Their self-efficacy boosts them that they can play well if they put the desired efforts. Thus as the result of their own initiatives they perform well. Similarly in medical sciences, the first and foremost tool of the successful operations is the self-reliance. If the doctors have complete trust on their skills, they can operate or treat their patients more efficiently. Likewise, in all walks of life self-efficacy is the driving engine of accomplishments. In any society student are the major assets that can lead their country towards progressive pace. Students' complete reliance on them boosts their energies to perform even academically well. 
The mode in which a student becomes successful has an effect on his own self-efficacy potential. In the classroom, for instance, low grades and other unconstructive evaluation of skills can minimize self-efficacy viewpoints (Self-Efficacy Beliefs and Career Development). Vialle (n.d.) found the relationship between the level of self-efficacy and educational performance of the students. He discovered that students having higher level of self-efficacy show much enhanced educational accomplishments than the students having lower selfefficacy level. He found that students who are self-relied and have complete confidence on their skills can manage the difficult situations, participate in class with full attention, and give preference to learn from their own experiences The students who have low self efficacy level, feel shy to participate in the class, hesitate to contribute in classroom discussion and isolated themselves in their studies.

The academic performance of the students depends on their self-efficacy. For instance, when the students promote to new semester they have got not any exact idea regarding the new courses. But accepting the changes and having the passion to learn new things enable them to step ahead. Through their self-confidence they lean to understand new things by putting some nominal efforts. Hence, it is important to find the association between self efficacy level of students and their educational performance. Current research has been undertaken to explore this relationship to contribute towards the academic research. This research would be a value addition to increase the academic performance of students by focusing on their self efficacy level.

\section{Literature Review}

The notion Self-efficacy depicts the self-reliance of persons on their own talent to take some specific initiatives, or completely use their capabilities and as result attain definite outcomes (Bandura, 1977; 1982; 1997). Efficacy determines the attitude to take some initializing steps, the determination power to overcome the significant troubles, and the energetic actions to chase the assigned responsibilities (Bandura, 1997). A lot of research has been conducted in diverse time periods and the results showed that self efficacy and performance are powerfully interconnected (Sadri \& Robertson, 1993; Pajares, 1996; Vrugt, Langereis, \& Hoogstraten, 1997). Similar sort of findings were given by other researchers as well, like Stajkovic \& Luthans (1998); Newby-Fraser \& Schlebusch (1998) and Manstead \& Van-Eekelen (1998) also found that there is significant relationship between one's self-efficacy level and his performance . These findings were further strengthened by Wolters \& Pintrich (1998) when they found significantly positive association between selfefficacy level and performance.

Many researchers (Pajares, 1996; Bandura, 1997; Lane \& Lane, 2001) found that the superior results of big five personality traits can be obtained by performing defined tasks as compared to broader job. Performing a task successfully demands the removal of difficulties coming forth as the job proceeds. This in turn requires profound skills, cognitive ability (the ability to accomplish a specific task ranging from simplest to complex level) and self- determination (self efficacy). But Lent \& Hackett (1987) found that there exist no such perfect circumstances that capitalize on the self-efficacy and performance association. Many studies were conducted in educational surroundings to throw a light on self efficacy decisions and the resultant performance. It has been observed that success in the latest areas to the students (such as the start of the course or selection of new subjects) relied on the capability to take know-how of new things, or on the self-efficacy potential arising from the previous academic output (Schunk et al., 1987; Zimmerman et al., 1992). In their grand analysis of the studies, Multon et al. (1991) found considerable associations between desired job performance and selfefficacy as compared to the assigned job.

This relationship was more clarified by the researches conducted by Lane and Lane (2001) and Lane et al. (2003). They proposed that the confidence of the students to pass the exam in which they were appearing for the first time was noteworthy associated with the performance of the students. It means that students were so much confident that they would pass the exam; no matter they were appearing in it for the first time. Hence, performance is associated with the self-efficacy level of the students. In reality analytical usefulness of self-efficacy suggests that knowing about the strategic value of self-efficacy could elevate the level of selfefficacy. There are fundamentally four bases of knowledge on which Self-efficacy viewpoint can be built-up (Bandura 1977, 1982, 1997). These bases are vicarious experiences (the experience gained by reading or hearing some other person); enactive mastery experience (the knowledge by doing the parallel jobs); verbal 
influence (speaking in such a way that other persons forced to listen and act); and physiological states (the states of the body). Research suggests that prior performance activities give rise to the generation of selfefficacy (Bandura, 1982).

Efficacy potential can be raised by performing well and it becomes lowered through poor performance. Selfefficacy is not only influenced by poor or successful performance, it takes the effect of how knowledge is evaluated by performing the simplest to complex tasks. A lot of factors must have an impact on the evaluation of knowledge by performing the simples to complex tasks. The significant factors are self-esteem and attribution. In simplest term Self-esteem means how people value themselves or what is their worth in their own eyes, or their level of self-appraisal, evaluation, and appreciation. Self-efficacy issues relate to the potential to accomplish some assigned tasks, or take some initiatives, or follow strategic actions. Mone, Baker, \& Jeffries (1995) showed that preference of individual objectives as well as performance attainment can not be forecasted through self-esteem or self-determination. But Bandura (1997) proved that the self-esteem and self-efficacy will be affirmatively connected if an individual has greater degree of self-efficacy in performing a task relating to his profession in which he has devoted a certain level of self-worth. The connection between one's self-efficacy level and his self-esteem is negative in the case where the self-worth is less devoted.

How knowledge is attributed. It is another factor that describes the relationship between one's level of selfefficacy and his performance and this factor must influence the relationship of two variables i.e. performance and level of self-efficacy. Weiner (1986) proposed that alternative potential measures did not take the effect of lack of effort which ultimately leads towards failure, although lack of capabilities to take initiatives can affect them. Bandura (1982) suggested that the accomplishment of similar performance level will possibly move up, lesser or encompass no influence on persons' self-efficacy levels depending upon how the concerned person self-assess these aspects. The basic aim of the present research was to explore the association between perceived academic performance and self-efficacy level of the students i.e. whether their self confidence of increase/decreases their performance level. The reason of this research conductance was to recognize and to make available outfitted description of the self-efficacy within the academic research field.

\section{Research Methodology}

This study has been conducted to explore the association between perceived academic performance and selfefficacy level of the students as it has been an un-explored research area in the Pakistan. To achieve research objectives students were selected as an obvious target population. Sample consisted of 250 university students. University students were chosen for sampling because this study basically highlights the academic performance of university students as a result of their perceived self efficacy level. Simple random sampling was used here. Structured questionnaire was used as data collection instrument. Major portion of the questionnaire had been taken form the research work done by Sherer et al. (1982). Out of 250 students, 212 students contributed in the data collection comprising 85\% response rate for the study. SPSS 16.0 was used for data analysis.

\section{Findings of the Study}

The results of the study are explained below.

Table 1 shows the frequencies of demographical traits of the respondents. As per findings of the study, majority of respondents were between $21-25$ years of the age (81.6\%), 14.6\% respondents were of 15-20 years and rest (3.8\%) were between 26-30 years. Majority of the respondents were male $(61.3 \%)$ and rest (38.7\%) were female students. While looking into the educational qualification, $60.8 \%$ of the respondents were bachelors, $32.2 \%$ were of master level, and remaining students i.e. $9 \%$ were of the M.phil level. 
Table 1: Frequencies of Demographical Traits

\begin{tabular}{llll}
\hline Variables & & Frequency & Percentage \\
\hline \multirow{2}{*}{ Age } & $15-20$ years & 31 & 14.6 \\
& $21-25$ years & 173 & 81.6 \\
& $26-30$ years & 8 & 3.8 \\
Gender & Male & 130 & 61.3 \\
& Female & 82 & 38.7 \\
Educational Level & Bachelors & 129 & 60.8 \\
& Masters & 64 & 32.2 \\
& M.phil & 19 & 9.0 \\
\hline
\end{tabular}

Table 2 shows the statistics of the factors of this study. Findings of the table show that students have positive feelings about their academic performance and believe that they are doing well academically (mean=3.65=agree). When inquired about the level of self-efficacy mean score of 3.31 shows that students are having neither positive nor negative view about their self-efficacy and view their self-efficacy level as neither high nor low.

Table 2: Descriptive statistics of the study variables

\begin{tabular}{lccc}
\hline Variables & Mean & Std. Deviation & $\mathbf{N}$ \\
\hline Academic Performance & 3.6562 & .62528 & 212 \\
Self-Efficacy & 3.3074 & .54756 & 212 \\
\hline
\end{tabular}

Table 3 shows the summarized resultant values of the regression analyses. Firstly, R Value (.189) shows a weak positive relationship between level of Self-efficacy (IV) and DV (educational Performance). As correlation coefficients of dependent and independent variables are always considered to be equivalent to the $\mathrm{R}$ value. Hence, $\mathrm{R}$ value (.189) depicts a weak positive correlation between IV (self-efficacy) and DV (academic performance).

R square value shows the percentage variation in DV that is caused by the IV. In this model, it is explicit that IV (Self-efficacy) causes only 3.6\% (.036) change in DV (academic performance) and rest of the portion is accounted for the other factors held constant in the model. This shows a weak dependency (3.6\%) of perceived academic performance of students upon their level of self-efficacy. Positive sign of B value (.216) shows that there exists a positive correlation between level of Self-efficacy (IV) and DV (educational Performance). P value (.006) for self-efficacy (IV) is below the significant level (.05). Hence, results suggest that there is a significant effect of students' level of self-efficacy (IV) on their perceived academic performance (DV) at the $\mathrm{p}<.05$ level for $[\mathrm{F}=7.783, \mathrm{t}=2.790]$.

Table 3: Impact of students' self-efficacy on their Academic Performance

\begin{tabular}{llllll}
\hline Independent Variable & $\mathbf{R}$ & $\mathbf{R}^{2}$ & $\mathbf{B}$ & $\mathbf{F}$ & $\mathbf{P}$ \\
\hline Self-efficacy & .189 & .036 & .216 & 7.783 & .006 \\
\hline
\end{tabular}

Dependant Variable $=$ Academic performance 


\section{Conclusion and Future Implications}

This study has been conducted to explore the association between perceived academic performance and selfefficacy level of the students as it has been an un-explored research area in the Pakistan i.e. whether their self confidence of students increase/decreases their performance level. To accomplish this plan, current research has been conducted. Through regression analysis, findings suggest that there is a considerable impact of students' level of self-efficacy (Independent variable) on their perceived academic performance (Dependent variable). Findings of the study establish a weak positive association between level of self-efficacy (Independent variable) and perceived academic performance (Dependent variable) as Independent variable causes only 3.6\% (.036) change in Dependent variable (academic performance). Hence, there is a weak dependency of perceived academic performance of students upon their level of self-efficacy.

Current research throws the light upon an unexplored research area in Pakistan. Future research implications could be made by comparing the self-efficacy level of students studying over public and private universities to see its impact on their educational performance. Other related factors such as self esteem or Big Five personality traits could be incorporated into the research model to see their moderating impact on the association between level of self efficacy and the educational performance of the students. This would certainly lead to the knowledge contribution towards academics' research and education management in Pakistan.

\section{References}

Bandura, A. (1977). Self-efficacy: Toward a unifying theory of behavioral change. Psychological Review, 84, 191-215.

Bandura, A. (1982). Self-efficacy mechanisms in human agency. American Psychologist, 37, 122-147.

Bandura, A. (1997). Self-efficacy: The exercise of control. New York: W. H. Freeman.

Csikszentmihalyi, M. (1997). Finding flow: The psychology of engagement with everyday life. New York: Basic Books.

Lane, A. M. (2002). Relationships between performance toward accomplishment and self-efficacy in amateur boxing. Perceptual and Motor Skills, 94, 1056.

Lane, A. M., Jones, L. \& Stevens, M. (2002). Coping with failure: The effects of self-esteem and coping on changes in self-efficacy. Journal of Sport Behavior, 25, 331-345.

Lane, J. \& Lane, A. M. (2001). Self-efficacy and academic performance. Social Behavior and Personality, 29, 687-694.

Lane, J., Lane, A. M. \& Cockerton, T. (2003). Prediction of academic performance from self-efficacy and performance accomplishments among master's degree students. Journal of Hospitality, Leisure, Sport and Tourism Education, 2, 113-118.

Lent, R. W. \& Hackett, G. (1987). Career self-efficacy: Empirical status and future directions. Journal of Vocational Behavior, 30, 347-382.

Manstead, A. S. R. \& Van-Eekelen, S. A. M. (1998). Distinguishing between perceived behavioral control and self-efficacy in the domain of academic intentions and behaviors. Journal of Applied Social Psychology, $28,1375-1392$.

Mone, M. A., Baker, D. D. \& Jeffries, F. (1995). Predictive validity and time dependency of selfefficacy, selfesteem, personal goals, and academic performance. Educational \& Psychological Measurement, 55, 716-727.

Multon, K. D., Brown, S. D. \& Lent, R. W. (1991). Relation of self-efficacy beliefs to academic outcomes: A metaanalytical investigation. Journal of Counseling Psychology, 38, 30-38.

Newby-Fraser, E. \& Schlebusch, L. (1998). Social support, self-efficacy and assertiveness as mediators of student stress. Journal of Human Behavior, 34, 61-69.

Pajares, F. (1996). Self-efficacy beliefs in academic settings. Review of Educational Research, 66, 543-578.

Rosenberg, M. (1965). Society and the adolescent child. Princeton, NJ: Princeton University Press.

Sadri, G. \& Robertson, I. T. (1993). Self-efficacy and work-related behavior: A review and metaanalysis. Applied Psychology, 42, 139-152.

Schunk, D. H., Hanson, A. R., \& Cox, P. D. (1987). Peer-model attributes and children's achievement behaviors. Journal of Educational Psychology, 79, 54-61. 
Self-Efficacy Beliefs and Career Development. (n.d). Retrieved June 8, 2011 from http://www.123helpme.com/view.asp?id=35824.

Sherer, M., Maddux, J.E., Mercandante, B., Prentice-Dunn, S., Jacobs, B. \& Rogers, R.W. (1982). The self-efficacy Scale: Construction and Validation. Psychological Reports, 51, 663-671.

Stajkovic, A. D., \& Luthans, F. (1998). Self-efficacy and work-related performance: A meta-analysis. Psychological Bulletin, 124, 240-261.

The Concept of Self-Efficacy. (n.d). Retrieved June 8, 2011 from http://www.123helpme.com/preview.asp?id=85270.

Vialle, W. (n.d). Retrieve June 8, 2011 from http://www.aare.edu.au/98pap/and98319.htm.

Vrugt, A. J., Langereis, M. P., \& Hoogstraten, J. (1997). Academic self-efficacy and malleability of relevant capabilities as predictors of exam performance. Journal of Experimental Education, 66, 61-72.

Weiner, B. (1986). An attributional theory of motivation and emotion. New York: Springer-Verlag.

Wolters, C. A., \& Pintrich, P. R. (1998). Contextual differences in student motivation and selfregulated learning in mathematics, English, and social studies classrooms. Instructional Science, 26, 27-47.

Zimmerman, B. J., Bandura, A., \& Martinez-Pons, M. (1992). Self-motivation for academic attainment: The role of self-efficacy beliefs and personal goal setting. American Educational Research Journal, 29, 663-676. 